\title{
Imagem e imagem: a instabilidade semântica no trabalho do ator. Algumas imprecisões, certos equívocos, e outras possibilidades no uso do termo
}

Image and image - semantic instability in the work of the actor. Certain inaccuracies, some misconceptions, and other possibilities around this term

Mariane Magno Ribas ${ }^{1}$ 


\section{Resumo}

O texto a seguir pretende distanciar o olhar e mobilizar o pensamento sobre o uso do termo "imagem" no trabalho criativo do ator, cuja utilização é cada vez mais frequente, tanto nos espaços artísticos e pedagógicos, quanto no cotidiano de um modo geral. Todavia, o uso recorrente e, às vezes, excessivo, torna o termo familiar e próximo demais. Decorrente dessa proximidade ocorrem algumas imprecisões que podem ser observadas como indefinições semânticas e também como a perda da conexão com a densidade artística e espiritual no corpo, ou seja, a imagem somática e artística que toca a dimensão arquetípica. Para diferenciar e distinguir imagens de um modo geral da Imagem artística o texto provocará o pensamento a partir de três diretrizes: alguns equívocos, certas possibilidades, e a aproximação possível da Imagem poética, o indizível.

Palavras-chave: Imaginação do ator; imagem artística; processo criativo

\section{Abstract}

The following text intends to distance the gaze and mobilize thought about the use of the term 'image' in the creative work of the actor, a term whose use is evermore frequent in artistic and pedagogical spaces as well as in daily life in general. However, a recurrent and sometimes excessive use makes the term overly familiar. Due to this closeness, certain inaccuracies occur that can be observed as semantic indefiniteness and a loss of connection with the artistic and spiritual density in the body, that is to say the somatic and artistic image that touches the archetypal dimension. In order to differentiate and distinguish 'image in general' from 'artistic image', this text will provoke thought from three ways perspectives: some misconceptions, certain possibilities and the possible approximation of the poetic image, the unspeakable in the creative work of the actor.

Keywords: The actor's imagination; artistic image; creative process

ISSN: 1414.5731

E-ISSN: 2358.6958

${ }^{1}$ Profa. Dra. Adjunta do Departamento de Artes Cênicas. Universidade Federal de Santa Marina (UFSM), RS. marianemagno@hotmail.com 


\section{Introdução}

Não precisamos dos poetas ou das psiques em crise para confirmar a atualidade e a força da Imagem e dos símbolos. A mais pálida da existência está repleta de símbolos, o mais 'realista' vive de imagens (Eliade, 1992, p.11).

O termo imagem, de um modo geral, pode ser utilizado nas realidades digitais e não necessariamente artísticas, mas, também, nas digitais artísticas; no universo audiovisual; na poesia; nas artes visuais; na gramática, como metáfora; no trabalho criativo do ator; e, ainda, relacionado aos aspectos vivos e subjetivos da realidade psicossomática, conforme encontrado nos estudos kelemanianos, feldenkraisianos, junguianos, lacanianos, artaudianos e, entre outros, também na realidade profunda e simbólica eliadiana, como aponta a epígrafe que inicia este texto. Fica evidente, portanto, que o termo "imagem" pode ser utilizado para se referir a uma realidade ou a um objeto externos ao corpo e também a uma realidade interna, sejam tais realidades psíquicas, emocionais, corporais, intelectuais, sensoriais, cinestésicas, sinestésicas, imaginárias, simbólicas ou poéticas.

O termo "imagem", como já dito, também é comumente utilizado para referir- se tanto a uma realidade sem vida quanto a um processo vivo. Interessa o artístico. Para isso, resgato das diversas possibilidades de uso do termo "imagem", a realidade psicossomática criativa como parte do todo - Imagem - e direciono o objetivo desse recorte à aproximação possível da realidade subjetiva apresentada por Eliade - as Imagens - dos processos sensíveis e psicossomáticos na imaginação do ator, sem, no entanto, dissociá-la, a realidade subjetiva, de sua forma. Dessa multiplicidade de imagens define-se, portanto, para este pequeno percurso, o termo Imagem (assim mesmo, em maiúsculo) com base eliadiana, aproximado do contexto técnico e criativo do trabalho do ator, querendo isso dizer, nos momentos vivos dos processos criativos, sejam eles em sala de aula, de treinamento, em laboratórios investigativos e também na cena.

Esta breve introdução aponta a complexidade e a multiplicidade de mundos e camadas que podemos acessar ao utilizar a palavra "imagem". Nesse sentido, o de acessar e criar mundos, o termo pode ser utilizado no processo de formação de atores também com diversos propósitos, em diversos espaços e referir-se a diversas coisas e também a diferentes camadas de uma mesma coisa, desde as mais formais do movimento corporal, até as camadas mais profundas, misteriosas e inapreensíveis dos movimentos e impulsos que emergem do interior do Corpo. O que importa, de fato, é o todo, a relação viva construída pelo ator, a cada vez, entre as camadas mais superficiais e evidentes até as mais subterrâneas da sua atuação. Em outras palavras, busca-se com o trabalho técnico do ator, através de suas camadas formais, físicas e estruturais um acesso vivo ao inapreensível, ao indizível, ao espontâneo.

De dentro desse território formal e paradoxalmente subjetivo, e que também é artístico, psicossomático, singular, vivo e pedagógico apontarei possíveis abordagens, influências e ressonâncias do uso do termo "imagem" na formação e no trabalho corporal criativo de atores. Todavia, algumas proposições considero caóticas, enquanto outras entendo como verdadeiramente provocadoras e organizadoras, tanto na prática em laboratórios investigativos quanto na organização do pensamen- 
to, sobretudo nos processos dos alunos iniciantes que estão criando as primeiras referências e formando suas bases práticas, teóricas e reflexivas.

Para tal propósito, inicio com um primeiro movimento que parte de certos aspectos básicos no uso do termo, cuja complexidade e imprecisões emergem de diferentes contextos. Neste sentido, por entender tais contextos como fundamentais, vejo que, quando não entendidos suficientemente, pode causar sérios e insistentes equívocos.

Na segunda investida, mobilizo o termo "imagem" relacionado a camadas densas e concretas do corpo e do espaço e, ainda, possíveis relações entre as diferentes realidades, a interna e a externa do corpo, cujas ações, por sua vez, apontam um direcionamento a uma aproximação possível do terceiro momento, o dos aspectos sutis que nos apontam o poético. Desse modo, refiro-me, por fim, àqueles aspectos subjetivos que dão vida à forma, aos impulsos interiores que emergem das energias do corpo. Em outros termos, à voz subjetiva que mobiliza a singularidade da expressividade poética.

Entendo como Imagem os aspectos formais vivos que não são apenas a sua forma plástica e física, ou seja, são formas detalhadas e cuidadosamente elaboradas, e que, de algum modo, emergem de processos singulares endógenos, e, ainda assim, paradoxalmente, abertos para diversas possibilidades de leitura. A Imagem, no trabaIho do ator, quando artística e verdadeira, não se conclui em si mesma, ela aponta, de algum modo, para a verticalidade do tempo e para a imensidão do espaço artístico. Artaud aponta um direcionamento desse mistério ao dizer que: "Todo sentimento é na verdade intraduzível. Expressá-lo é traí-lo. Mas traduzi-lo é dissimulá-lo. A expressão verdadeira esconde o que ela manifesta" (Artaud, 1999, p. 79).

\section{Primeiro movimento: algumas imprecisões e certos equívocos}

A utilização do termo "imagem" de modo genérico, sem suficiente clareza a qual tipo de imagem, ou a qual aspecto do trabalho criativo se refere, ao propor algo para o aluno-ator, muito provavelmente gerará diversas imprecisões e até graves confusões no entendimento sobre seu trabalho corporal, espacial, dramatúrgico, conceitual, estético e teórico. A proposição da palavra "imagem" em processos práticos pode afetar de modo direto e muito profundo o agir do ator sob sua imaginação. Também pode conduzi-lo a processos equivocados e fantasiosos.

Em outras palavras, a utilização da palavra "imagem" pode direcionar e/ou propor aos atores investigações verdadeiramente criativas, ou, no sentido oposto, conduzi-los a estados corporais caóticos que, por consequência, gerariam entendimentos caóticos e reflexões com bases instáveis. Nesse contexto, penso que o entendimento corporal, construído e desenvolvido pela prática e com seriedade, é determinante para uma boa teorização. Sob essa perspectiva, aumentam as responsabilidades daquele que usa o termo em contextos de formação.

Em certos casos, processos artísticos dessa natureza somática e criativa, quando mal conduzidos, mal orientados e/ou mal entendidos também podem estabelecer equívocos bem mais sérios e causar consequências mais perigosas, como, por exemplo, levar o artista a não saber identificar, em si mesmo, o estado artístico criador. Pela falta de referência prática, ele, o artista, pode confundir os processos 
verdadeiros da imaginação, entre outras coisas, com pensamentos fantasiosos.

Entendo ser relevante abrir um espaço para evidenciar que o estado criador do ator é de natureza artística, exigindo elaboração estética e, por isso, atinge uma dimensão "suprapessoal" (Jung,1971, p. 60). O termo "psicossomático", no trabalho do ator, portanto, está comprometido com essa natureza criativa. Certamente, toda ação humana também é uma ação psicológica, mas, as ações artísticas, ainda que processadas e elaboradas como materialidade humana, estão além do ego e a serviço de processos criativos. Nesse contexto, o olhar, o agir, o mover, o falar, o cantar, o calar, o entender, o assimilar e o respirar são processos criativos artísticos tanto quanto os impulsos de quem atua e, ainda, os conteúdos em processamento criativo. Pelo contexto inserido e pelo processamento passado, tais ações e seus conteúdos subjetivos - no momento em que atuam - não são personalidades, também não são sintomas e, tampouco, patologias; são, sim, Imagens artísticas, são Imagens poéticas. Nesse contexto criativo, se se referir à cena, haverá comprometimento estético e artístico. Seguindo pela visão junguiana, "a pergunta sobre o que é a arte em si, não pode ser objeto de considerações psicológicas, mas apenas estético artísticas" (Jung, 1971, p. 54). Nesse sentido, o estado psicossomático artístico, seu processo de criação e resultados devem ser entendidos e diferenciados das ações da personalidade pois,

A insistência no pessoal, surgida da pergunta sobre a causalidade pessoal, é totalmente inadequada em relação à obra de arte, já que ela não é um ser humano mas algo suprapessoal. É uma coisa não uma personalidade e, por isso, não pode ser julgado por critério pessoal. A verdadeira obra de arte tem inclusive um sentido especial no fato de poder se libertar das estreitezas e dificuldades insuperáveis de tudo o que seja pessoal, elevando-se para além do efêmero do apenas pessoal (Jung, 1971, p.60).

Retornando ao fato de que, de um modo insistente, o termo "imagem" é cada vez mais presente e banalizado cotidianamente, esse entendimento cultural da imagem como a representação de algo que não é a coisa em si, entra para sala de trabalho junto com o corpo e com o agir do ator, no pensamento do ator, na sensibilidade do ator e também na imaginação do ator. Lamentavelmente, às vezes, como únicas referências no uso do termo. Insisto dizer, todavia, que o conceito "imagem" relacionado a diversas mídias, a diferentes linguagens e aos dispositivos digitais de uso diário nas mãos - no corpo - do aluno-ator, está claramente entendido e, culturalmente, também forma o imaginário do ator. Neste contexto, a utilização do termo refere-se a realidades externas ao corpo, e não necessariamente poéticas, ainda que ao serem observadas, tais realidades externas, possam provocar ressonância corporal, sensível e imaginária.

As imprecisões acontecem, os fios conceituais se enroscam, e se confundem, quando não fazemos tal distinção básica no uso do termo na hora do trabalho somático criativo, ou seja, das imagens propostas e/ou externas ao corpo do ator, das imagens que emergem do self corporal em trabalho criativo e da Imagem, entendida como o todo indissociável. Imprecisões e confusões dessa natureza podem acontecer simplesmente pela insuficiente clareza ao que, de fato, estamos nos referindo quando utilizamos a palavra "imagem" em sala de trabalho com atores. De 
modo, geral o termo pode referir-se a uma realidade interna ou externa, objetiva ou subjetiva. Todavia, sem saber suficientemente qual conceito está sendo operacionalizado pelo ator, ou, sob outra perspectiva, em quais aspectos se propõe que eles, os atores, direcionem e concentrem sua atenção criadora e sua imaginação, poderão ocorrer desde indecisões e imprecisões até equívocos básicos de entendimento. Utilizar a palavra "imagem" de modo genérico em uma sala de trabalho de aluno-atores iniciantes e em processo criativo, muito possivelmente, na mesma hora, o caos técnico, sensível e teórico se instaurará. O termo pode ser apreendido pelos atores de modo tão amplo quanto ouvir a palavra "vida", cuja ressonância poderia ser vaga demais. Neste contexto impreciso, a energia criativa que deveria gerar e canalizar mais vida ao processo criativo poderia gerar confusões e criar generalidades.

Diante disso, objetivo identificar e distinguir alguns fios que conduzem a trama semântica, artística, e o pensamento no uso do termo imagem, cujas ações, em certos momentos, observo como um complexo emaranhado, apertado como um nó conceitual que, ao invés de libertar o estado criador dos atores, acaba por bloquear seus corpos, seus movimentos, suas vozes - suas Imagens. Viso, por conseguinte, desapertar e identificar alguns fios intencionando abrir espaços vazios para que seja possível, se não desenredá-los totalmente, reconhecê-los, observá-los e distingui-los suficientemente. Pois bem, ironicamente, voltando à imensidão do termo "Imagem", é importante dizer que, também reside nela - além do risco de cair na generalidade do tudo que não é nada - a imensidão de seu potencial vivo e criativo. Evidencio, portanto, a riqueza da palavra "imagem" e suas múltiplas possibilidades criativas, tanto quanto a ação conjunta com a intuição e/ou clareza conceitual e/ou um propósito definido para um direcionamento criativo. O termo "imagem", quando não é suficientemente entendido pelo aluno-ator durante o processo criativo, pode dispersar sua concentração, oscilar ou se fixar como imagem figurativa, ilustração, simulação da ação, mímica, ou, ainda, algum tipo de enquadramento como a fotografia, etc. Em qualquer um destes contextos está em referência o sentido da visão do ator e, com isso, há um certo entendimento de representação que poderá afastar sua concentração dos outros sentidos. Está implícito, portanto, nesse entendimento de imagem, aspectos codificados como uma figura, ou seja, há um entendimento formal e resgatável implicado. Às vezes, imagem, nessa camada representativa, também prende a atenção do ator apenas com um significado, enquanto que a Imagem é o todo, forma e energia indissociáveis e de natureza simbólica.

São diversas as possibilidades de utilização do termo também na realidade interna, psicossomática e criativa do trabalho do ator. Talvez seja a imprecisão na escolha e no uso das imagens uma das razões que movem e apertam ainda mais esse emaranhado, ou seja, a utilização inexata, confusa e até indiscriminada de um termo cada vez mais acostumado. Podemos pensar ao menos em dois sentidos, o das imagens propostas ao ator e o das imagens que emergem do trabalho somático do ator. Certamente, os processos criativos são espaços questionadores, provocadores e de liberdade. A intenção não é fechar uma estabilização semântica para o termo, e também não é problematizar e valorar a multiplicidade no uso do termo e sua pluralidade conceitual e adjetivos, mas, sim, distanciar e mobilizar o pensamen- 
to visando precisão na escolha. Em vista disso, "imagem" pode se referir: ao espaço físico $^{2}$; a uma qualidade do movimento ${ }^{3}$; ao entendimento rítmico ${ }^{4}$; aos impulsos como aspectos vivos subjetivos, sensíveis e criadores 5; à ideia central do texto ou da cena $^{6}$; à concepção7; a uma representação ${ }^{8}$; a um pensamento filosófico ${ }^{9}$; a diversas coisas ao mesmo tempo ${ }^{10}$, ou, ainda, a diferentes camadas de uma mesma coisa.

Pois bem, ao utilizar o termo "imagem", sobretudo nos processos de formação de atores, se não houver clareza de propósito e direcionamento suficientes, ao que de fato queremos referir ou provocar na atenção e na imaginação com o uso do termo, o ator poderá se perder e agir de modo confuso, impreciso e sem sentido. Esta imprecisão pode dissipar a atenção, a concentração e a imaginação. Em momentos assim, uma das possibilidades de entendimento equivocado é o ator, durante os laboratórios investigativos, começar a racionalizar excessivamente e atuar predominantemente a partir da sua função intelectual. Assim, o pensamento irá movê-lo por essa via de entendimento abstrato que poderá deixar seu corpo cada vez mais desabitado e perdido. Quando isso ocorre, alguns atores agem corporalmente movidos pela função intelectual e começam a evocar fantasias da sua memória, como, por exemplo, o pensamento de algumas imagens. Nesses casos, podem ser figuras, lembranças ou qualquer conteúdo abstrato em movimento na mente. Assim, começam os processos de pensar e raciocinar sobre imagens que não estão em sintonia, tampouco em ressonância, com o trabalho corporal sensível.

Atuando por essa via, eles de fato tentam, equivocadamente, forçar um pensamento a imaginar ao invés de direcionar a atenção à sensibilidade e à criação que emerge do corpo quando em processos criativos. Continuando a agir assim, com o pensamento predominantemente ativo e como referência e, às vezes, como um guia mesmo, estará estabelecida uma perigosa confusão no agir e no pensar. Com a função pensamento predominando, o ator distancia sua atenção da materialidade corporal, do entendimento rítmico, da sua sensorialidade, da sua sensualidade e da sua intuição criativa. Por esse modo, apertando o emaranhado dos fios de imagens, equivocadamente pode acreditar estar em processos somáticos de imaginação. Em outras palavras, o ator tenta justificar em palavras e em explicações, às vezes fantasiosas, aquilo que só a sensibilidade poderia acessar, despertar e vivenciar - as Imagens poéticas que emergem das profundezas misteriosas do Corpo.

\footnotetext{
${ }^{2}$ Atenção do ator provocada imageticamente a algum aspectos externos como distâncias, percursos, iluminação, objetos, desenho da cena, como, por exemplo, figuras e/ou linhas, níveis, planos; ou simplesmente referir a cenografia.

${ }^{3}$ Atenção do ator direcionada ao sensível, que pode ser confundida com abstração e pensamento; ou um movimento com certa qualidade, como, por exemplo: água, vermelho, liso.

${ }^{4}$ Atenção do ator provocada ao entendimento do ritmo a partir de algum elemento, como, por exemplo: na realidade interna como a internalização do ritmo, na realidade externa como audição, no trabalhar sob ou sobre a pulsação do movimento, ou uma certa qualidade rítmica como movimento intermitente, ou a partir do termo "ritmo" como buscar o ritmo da ação, do texto ou do movimento etc.

${ }^{5}$ Atenção do ator concentrada e trabalhada a partir das 'Imagens' que emergem da realidade interna, imagens arcaicas que emergem do sel criador, fluxo dinâmico da imaginação, uma compreensão sensível da respiração ou qualquer outro elemento técnico.

${ }^{6}$ Atenção do ator nas camadas da realidade dramatúrgica.

${ }^{7}$ Sentido que funde de modo criativo todos os elementos constituintes da cena gerando a concepção do espetáculo.

${ }^{8}$ Atenção do ator no trabalho sobre algum elemento ou aspecto mais formal, como mímica, partitura de ações, desenho do movimento pelo espaço.

${ }^{9}$ Atenção direcionada na realidade reflexiva e abstrata que pode conduzir um pensamento e entendimento mais complexo do conteúdo elaborado, seja de uma dramaturgia literária ou de qualquer natureza.

${ }^{10}$ Atenção do ator imprecisa ou difusa nas múltiplas realidades que podem sintetizar uma ideia ou gerar imprecisões e/ou equívocos.
} 
O pensamento reflexivo e a materialidade corporal sensível são camadas e momentos importantes que compõem o entendimento do processo criativo. Porém, são estados e momentos distintos do trabalho que, obviamente, visam a fusão criativa concebida como materialidade estética. A atuação predominantemente linear e mental distancia, portanto, a atenção do ator da realidade cinestésica, sensível, estética e sensória. Atuando assim, a mente utiliza energia, forças da realidade corporal que afastam do agir somático, aquele aspecto genuíno que emerge de conexões profundas em si mesmo e das pequenas percepções corporais.

Nesses momentos, é possível observar e identificar claramente um corpo quando, agindo assim, apresenta junto um certo desconforto e resistência no agir, às vezes com bloqueios muito evidentes. Tal desajuste tem repercussão em seus aspectos mais densos e também nos técnicos. Um olhar treinado reconhece e identifica de modo muito evidente um corpo em processos vivo de imaginação poética e em fluxo de imagens, tanto quanto um corpo bloqueado que sofre ao tentar impor um pensamento fechado e duro como materialidade somática e sensível. $E$, um espectador atento, mesmo que não saiba dissecar os elementos constituintes do movimento, sabe, sim, indubitavelmente, discernir um movimento vivo mobilizando imagens de uma imaginação sem Imagens e fechada. Tais diferenças, de abordagem e de linguagem, podem ser reconhecidas e identificadas na postura, no tônus muscular, na rigidez corporal, na rigidez do pensamento, no descompasso não intencional entre o agir e o pensar, e, inquestionavelmente, na qualidade da produção vocal.

Outra possibilidade de entendimento caótico com o uso do termo imagem comum de se ver prende o termo apenas no sentido da visão. Desse modo, os atores que criam imagens por outros sentidos podem ficar perdidos e confusos por não conseguirem nem ver nem enxergar nada. Às vezes porque ouviram ou apenas porque (mal) entenderam que teriam de ver imagens. Esse entendimento meramente literal também pode ser um equívoco, ironicamente, ainda que seja possível e vivo. Tal entendimento parcial, ingênuo, fantasioso e equivocado, que limita, e por isso reduz, a imaginação apenas ao compromisso de literalmente ver coisas, ou seja, que necessariamente sua imaginação the apresentaria e reapresentaria a mesma visão (a imagem) ocorre, a meu ver, pela ausência ou insuficiência de referências corporais sensíveis - psicossomáticas e teóricas do termo.

Trata-se, portanto, da falta de vivência da imagem a partir de um impulso vivo desenvolvido como realidade corporal, como realidade artística, libertadora e poética no trabalho somático e criativo. Para esse entendimento corporal é preciso passar pela experiência, é preciso viver e sentir aquilo que atravessa o corpo aberto e disponível ao processo criativo. Pois é, do mesmo modo que o termo imagem é bastante amplo, os processos criativos e corporais são singulares. Em outros termos, é necessário balizar que o processo em questão é criativo e não científico, ainda que existam critérios, fundamentos, princípios e procedimentos, cada ator e cada processo criativo provocam a imaginação e a subjetividade do corpo de um modo específico, atingindo respostas igualmente singulares. Assim atua a misteriosa natureza criadora.

Essa natureza misteriosa encontra proximidade em Tarkovski (1998, p.122, quando ele diz: 
É difícil imaginar que um conceito como imagem artística possa ser expresso através de uma tese precisa, fácil formular e de compreender. Não é possível fazê-lo, e ninguém desejaria que o fosse. Posso apenas dizer que a imagem avança para o infinito, e leva para o absoluto. Mesmo aquilo que se conhece como "ideia" da imagem, em sua multiplicidade de dimensões e significados, não pode, pela própria natureza das coisas, ser colocado em palavras. Porém, encontra expressão na arte.

Apontadas algumas possibilidades no entendimento metafórico, literal, representativo, indeciso e preciso de linguagem, ou criativo na proposição e no entendimento da palavra imagem, aponto uma outra possibilidade de equívoco. Dessa vez, não em relação aos diferentes contextos, mas, sim, com a provocação da Imagem do trabalho somático do ator. Nesse caso ela pode atuar como um símbolo, ou seja, ainda que possua aspectos codificados e objetivos, seu núcleo é vivo e possui energia em movimento, por isso permanecerá provocando mais movimento. Querendo isso dizer que, como todo símbolo, a Imagem, no trabalho somático e criativo do ator, também é parcialmente enigmática e parcialmente insolúvel.

Continuando nesse sentido que aproxima o entendimento simbólico do trabalho do ator, outro equívoco pode acontecer quando se toma uma parte, uma imagem, pelo todo. Exemplifico: os atores pouco experientes, quando em laboratório, entram em processo criativo e entendem ou são orientados para "segurar isso", ou "segurar a imagem" ou, ainda para "guardar essa imagem". Ora, nesses casos, obviamente, o que interessa é a sensibilidade e o estado criador, ou seja, concentrar a atenção e a imaginação no estado criador - entrar no fluxo dinâmico da imaginação - seja a serviço de uma dramaturgia a priori ou de uma dramaturgia em construção. O que de fato importa é entrar em conexão com os movimentos sensíveis e poético do corpo e, neste caso, a Imagem vinculada a imaginação do ator não é uma figura, ou uma representação, tampouco uma ilustração ou a memorização de parte, mas, sim, o todo que inclui uma parte viva, aberta e que gera um estado dinâmico. A Imagem eliadiana, mesmo que trabalhada em uma partitura corporal detalhadamente codificada, pode ser aproximada do trabalho do ator e ser entendida como fluxo dinâmico, como um processo vivo e profundo, cujo contexto não impõe um significado ou um entendimento fechado mas, sim, um sentido provocador.

Seguindo com o pensamento eliadiano: "No plano da dialética da Imagem, toda redução exclusiva é uma aberração" (Eliade, 1991, p. 12). Dito isto, considerando estes processos de imaginação dinâmica no trabalho do ator, poderia ser um equívoco se referir a eles como uma única imagem memorizada, congelando na consciência como lembrança apenas um fragmento do processo. Isto poderia ser entendido com cristalizar parte de um fluxo que é dinâmico, deixando de fora a energia, o movimento e a mutabilidade dinâmica, presente em tudo que é vivo.

Para prosseguir, resgato Bachelard (2001, p. 02), ao dizer que "[...] uma imagem estável e acabada corta as asas à imaginação". Memória, nesse contexto criador e psicossomático, acessa a abertura da imaginação criadora com energia genuína. 
É então a Imagem em si, enquanto conjunto de significações, que é verdadeira, e não uma única das suas manifestações ou um único de seus inúmeros planos de referências. Traduzir uma Imagem na sua terminologia concreta, reduzindo-a a um único dos seus planos referenciais, é pior que mutilá-la, é aniquilá-la, anulá-la como instrumento de conhecimento. (Eliade, 1991, p. 11-12)

A Imagem também pode ser entendida como uma certa Voz que emerge de dentro da voz. Nesse sentido, é necessário evidenciar, todavia, o ato de confundir a contaminação ou a ressonância da voz com o dizer e também com a voz propriamente dita. Imagem pode ser entendida como um dizer imprevisto, singular e irreprodutível que emerge do self somático no corpo poético do ator, a cada vez. Também pode ser entendido como aquele elemento alquímico que torna potente e singular um material conhecido. Imagem pode ser um estado que conecta ao "Confesso ou não-confesso, consciente ou inconsciente, o estado poético, um estado transcendente de vida, [...]" (Artaud, 1999, p.142).

\section{II.Segundo movimento: o corpo e algumas camadas densas e concretas da imagem}

O corpo do ator pode ser pensado e trabalhado didática e criativamente a partir de imagens que the são propostas ${ }^{11}$, cuja abordagem pode acontecer a partir de aspectos mais densos, como, por exemplo, o do movimento corporal, o de um entendimento muscular ou ósseo, ou, ainda, das sensações, etc. É possível pensar em uma abordagem pedagógica e também sensivel a partir da proposição de imagens ${ }^{12}$ que também visam a uma metodologia de abordagem e compreensão a partir da técnica, como por exemplo, as imagens para trabalhar exercícios de coordenação ${ }^{13}$; imagens para exercícios que visam investigar e criar relações do corpo com o espaço físico ${ }^{14}$, imagens que propõem investigar e criar relações do corpo em relação a outros atores ${ }^{15}$, imagens que proponham criar relações com objetos ${ }^{16}$; imagens que desenvolvam as habilidades como a expressividade vocal ${ }^{17}$; imagens associadas a procedimentos que trabalhem habilidades corporais mais complexas e demoradas de construir corporalmente ${ }^{18}$.

Os procedimentos pedagógicos, ainda que inúmeros, que utilizam o termo "imagem" para atingir o todo a partir de uma parte, seja como forma codificada, seja como ideia, quando propostos de modo claro, contribuem igualmente para a elaboração da clareza no direcionamento do trabalho corporal criativo. Neste sentido, o trabalho com as imagens propostas, relacionado às camadas mais densas e sutis do

\footnotetext{
${ }^{11}$ Nesse contexto, imagens propostas é tão amplo quanto falar processo criativo e sob essa perspectiva, imagens propostas podem ser textos, fotos, desenhos, vídeos, movimentos, cores, sons, ritmos, melodias, poemas, objetos, dinâmicas, qualidades de movimento, metáforas, etc.

${ }^{13}$ Por exemplo, os procedimentos que visam o desenvolvimento de habilidades de movimentos corporais e ampliação de repertório de movimentos.

${ }^{14}$ Nesse sentido, pode ser relações de diversas naturezas, como por exemplo, investigar diferentes velocidades, níveis e planos ou criar objetivos dentro de um certo percurso a partir da proposição de imagens. "Ao trabalhar o corpo num espaço especial destinado a sua conscientização, o corpo passa a ser vivido com seu "espírito" , com sua energia e suas manifestações afetivas, intuitivas, imagéticas, etc." (Almeida, 2009, p.72).

${ }^{15}$ Como por exemplo improvisações e reações/ jogo a partir do contato físico, do olhar e/ou da voz

${ }^{16}$ Como, por exemplo, investigações de dinâmicas com objetos como ações, intensões, diferentes velocidades, etc.

${ }^{17}$ Elementos como fonação, articulação, afinação e projeção e também laboratórios investigativos e criativos com o trabalho vocal.

${ }^{18} \mathrm{Como}$, por exemplo, acrobacias e certas formações em técnicas de dança.
} 
corpo, pode atuar como libertador e também como via de acesso do estado criativo, às Imagens, melhor seria dizer, aos processos da imaginação dinâmica do ator.

Elementos técnicos como sentido, ordem rítmica, intenção, objetivo, partitura de movimentos, também podem ser referidos como imagens e, nestes contextos, elas operam tanto nas camadas densas, concretas e objetivas quanto também visam tocar o sensível. Neste sentido metodológico, ao determinar e propor aos atores caminhos que desenvolvam habilidades técnicas, que chamo de aspectos mais densos e tangíveis pela sua materialidade e concretude, objetiva-se, de fato, um comprometimento muito refinado da sua concentração, da sua atenção-em-corpo naquilo que o ator faz, ou que por ele se faz. Com isso, quer-se ativar sua imaginação e quer-se provocá-lo a acessar e a trabalhar aberto as suas "Imagens'.

Tal objetivo subjetivo obviamente não invalida a necessidade dos procedimentos técnicos ${ }^{19}$, sejam eles quais forem. Ao contrário, entendo-os como libertadores, como plataformas aos voos poéticos da imaginação e também como ponto de retorno e de pouso. Entendo-os, os estudos da imagem, como forma elaborada, como necessários e indispensáveis para construção técnica, cujo domínio pode agir como um caminho que também funcionaria como um portal que, por sua vez, provocaria o ator a perceber e a agir a partir dos impulsos criativos e poéticos, que poderiam ser pensados como Imagens singulares, Imagens poéticas que despertam misteriosamente da imensidão do Corpo. Querendo isso dizer que o entendimento metodológico dos aspectos técnicos construídos pela insistência da prática consciente pode, a partir dos aspectos densos e/ ou formais, acessar camadas mais sutis e inconscientes. Neste sentido criador e artístico, as Imagens podem ser vivenciadas subjetivamente como um portal que se abre e transporta o ator a um outro mundo, o mundo das Imagens e da imaginação.

Ainda sobre os aspectos subjetivos, ao acessar este estado criativo da imaginação é possível experienciar simultaneamente um estado de transformações alquímicas e paradoxais, como, por exemplo, de identificação e de estranhamento, e isso pode ocorrer porque entrar em fluxo da imaginação poética é tocar o criativo, o subconsciente criador, um mundo vivo autógeno que acontece a partir de um processo endógeno sensível.

Diante disso, é possível pensar a partir de uma latência coletiva que, quando treinamos as habilidades corporais do ator, objetivamos, sim, - com tanta repetição e treinamento - que a subjetividade venha à tona preenchendo e moldando, como que justificando o trabalho e o desenho corporal. Trabalhamos a partitura corporal, mas queremos a força da Imagem artística, ou seja, um conteúdo que venha das profundezas arcaicas do corpo e transborde pela sua pele, re(modele) e re(crie) seus movimentos; um aspecto espontâneo e singular de cada momento.

Treinamos habilidades vocais na formação de atores e objetivamos aquilo que, por meio das vibrações sonoras vocais, inquestionável e corporalmente, nos atravessa sonoramente como vibração e impacto sensorial. Queremos, ainda, aquilo que está aquém e além da palavra; queremos ouvir o canto, queremos ouvir o grito, que-

\footnotetext{
${ }^{19}$ Desenvolvimento de habilidades físicas e ampliação da consciência e do repertório de movimentos corporais.
} 
remos ouvir o lamento, queremos sentir o indizível, cuja ação pode ressoar e repercutir em lugares desconhecidos ou adormecidos. Queremos ouvir e sentir o silêncio de onde vem e para onde vai a Voz.

Treinamos a exploração e o domínio do corpo do ator sobre o espaço físico e visamos por meio desse entendimento técnico o entendimento e a criação do espaço de ação, do espaço da cena, do espaço da narrativa, do espaço do acontecimento. Queremos de fato, com o estudo detalhado de tantos espaços, despertar as energias e as Imagens; visamos, sim, o espaço poético.

Há, ainda, um elemento técnico fundamental que pode ser abordado e trabalhado a partir das suas camadas densas - as musculares - mas que quando entendido em seus aspectos vitais e sutis pode conduzir o suporte técnico à ação poética. Ao entendermos plenamente a respiração do movimento ou da ação podemos conectar com a camada mais profunda do corpo.

Nesse sentido, dessa busca espiritual e arquetípica é possível aproximar as Imagens eliadianas também do pensamento afetivo, do atletismo afetivo proposto por Artaud: "Enquanto o atleta se apoia para correr, o ator se apoia para lançar uma imprecação espasmódica, mas cujo curso é jogado para o interior" (Artaud, 1999, p. 151). Em momentos como esses, não há bloqueios musculares nem de qualquer natureza, não há resistências, há apenas e incontestavelmente um corpo vivo e em movimento poético.

\section{Terceiro movimento: um direcionamento ao sutil e uma aproximação aos aspectos vivos das Imagens}

Escrever sobre os aspectos sutis e sensíveis é correr vários riscos, dada a singularidade e espontaneidade de cada momento poético, cuja complexa investida atua em solo vivo e exige paradoxalmente flexibilidade, abertura e firmeza na lógica conceitual, e, ainda, uma certa objetividade de abordagem. Nesse sentido, reafirmo, mais uma vez com o pensamento eliadiano, que

Não é necessário utilizar as descobertas da psicologia profunda ou a técnica surrealista da escrita automática para provar a sobrevivência subconsciente, no homem moderno, de uma mitologia abundante e, na nossa opinião, de um valor espiritual superior à sua vida "consciente.” (Eliade, 1991, p. 12)

Dito isso, cabe evidenciar que aproximar a Imagem eliadiana dos aspectos sutis nos processos criativos de atores é também entrar em solo pantanoso, energético, simbólico, de natureza dinâmica e ação mutante. Nesses momentos de criação, os movimentos da imaginação estão ativos e são espaços abertos, subjetivos e arquetípicos é possível pensá-los como concentração da atenção direcionada e envolvida pelos caminhos da imaginação. Para Almeida (2009, p. 73),

[...] concentrar-se no corpo significa deixar a consciência impregnar-se pelos movimentos sutis do corpo, que também são os movimentos sutis do espírito agindo sobre o corpo. A consciência, que surge dessa percepção simultânea do corpo e do espírito, se abre tanto para os processos internos quanto para seu entrelaçamento com o mundo externo. Usamos aqui a palavra espírito no sentido junguiano de plano arquetípico. 
Por isso, são espaços vivos e potentes para gerar mais vida. Por essa via viva que é a prática do trabalho corporal do ator, a Imagem não pode ser entendida como uma forma fechada totalmente contornável e congelada. Sua singularidade, portanto, advém dos aspectos genuínos existentes apenas na energia do momento de cada experiência; daí sua singularidade viva gerada por processos endógenos, cuja energia quando não é suficientemente elaborada e direcionada mantém-se caótica ou fechada. Não há sentido, deste modo, em cristalizar na memória, como lembrança um de seus aspectos formais, uma imagem, e entendê-la como o todo, se a Imagem a qual se refere é acessada por uma certa qualidade energética, é da ordem da sensibilidade e por isso apresenta conteúdos que emergem do self somático ${ }^{20}$.A Imagem na realidade subjetiva e em processos criativos de atores não é necessariamente uma figura e nem apenas o seu recorte ou contorno, mas, sim, um fluxo dinâmico que é ativado nas profundezas escuras do corpo em processo criativo.

É preciso, todavia, cuidado e seriedade ao utilizar a expressão "fluxo dinâmico" e dissociá-la do ingênuo entendimento que isso significaria que vale qualquer coisa e que não há critérios. Ainda que os critérios em uma experiência mais refinada sejam entendidos durante o próprio fazer criativo. Tampouco, obviamente, farei referência a qualquer alteração do estado psicossomático provocado pela adição de substâncias químicas de qualquer natureza. Fluxo dinâmico nos processos criativos da imaginação do ator pode ser ativado com o trabalho prático e sensível. Fluxo dinâmico da imaginação se afasta, portanto, de pensamento fantasioso e caótico e requer algum fundamento técnico, prático, somático, sensível e organizador. Arrisco utilizar o conceito organizador para me referir ao processo criativo pois, ainda que o mergulho no caos seja parte do processo criativo; ainda que objetive-se criar cenicamente e/ou corporalmente o caos, em ambos os casos será necessário um entendimento sensível que, como tal, impõe seus critérios, seus sentidos estéticos e valores artísticos a serem detalhadamente entendidos e cuidadosamente elaborados. Fluxo dinâmico da imaginação do ator também não é sinônimo de ritmo acelerado, mas a proposição de que a Imagem poética nunca está sozinha, ela (Imagem poética) é viva, autônoma, com aspectos genuínos e provocadores de outras tantas.

Neste sentido, ao utilizar a expressão "imagem poética" aproxima-se a Imagem eliadiana, tarkosvskiana, artaudiana não só ao trabalho somático criativo do ator, mas também à verticalidade e à imagem poética bachelardianas.

Sem dúvida, em sua vida prodigiosa, o imaginário cria imagens, mas apresenta-se sempre como algo além de suas imagens, é sempre um pouco mais que suas imagens. O poema é essencialmente uma aspiração a imagens novas. (Bachelard, 2001, p. 02)

Para Eliade (1991, p. 16),

"Ter imaginação" é gozar de uma riqueza interior, de um fluxo ininterrupto e espontâneo de imagens. Porém, espontaneidade não quer dizer invenção arbitrária.

${ }^{20}$ Sel somático, inconsciente somático, ver: Zimermmann (org) 2009. 
Ter imaginação é ver o mundo na sua totalidade; pois as Imagens tem o poder e a missão de mostrar tudo o que permanece refratário ao conceito. Isso explica a desgraça e a ruína do homem a quem "falta imaginação"; ele é cortado da realidade profunda da vida e de sua própria alma.

A natureza desse terceiro e último movimento cuja realidade é viva flexível e carregada de subjetividade reafirma que estou direcionando a escrita ao centro da natureza somática criativa, ou seja, gradativamente direcionando e aproximando o pensamento no sentido do inconsciente somático como um corpo energético e provocador dos estados poéticos, sem, no entanto, dissociá-lo de sua melhor forma. Continuando por esse sentido, sigo de mãos dadas com o treinamento corporal entendendo-o como um meio de domínio técnico e também como possibilidade de conexão às energias mais profundas do corpo, aos seus impulsos e às suas Imagens sabendo, por isso, buscar um direcionamento estético. Isto significa que um certo trabalho técnico e somático pode atuar como meio de acesso ao estado poético - as Imagens poéticas do corpo, o imenso e vertical que instaura-se no e através do corpo. Ao escrever imenso e vertical, meu corpo, sentado em frente a tela, revive, como consciência sensível, as palavras de Gil (2000, p. 65) quando diz:

A dimensão da profundidade distingue radicalmente o espaço do corpo do espaço objetivo. Porque não se trata de uma profundidade mensurável [...]. O que é próprio dessa profundidade é ligar-se ao lugar, dizendo-se então topológica: é uma certa ligação do corpo com o lugar que escava nele sua profundidade.

Nesse contexto, o tempo poético não é horizontal. Ele não é mais duração, pois sua linearidade é rompida pelos processos da imaginação e da criação. Assim, a verticalidade da Imagem poética cria um abismo vivo entre duas linearidades, a do antes e a do depois. Ela, verticalidade, é possível corporalmente pela vivência sensível, que também pode ser pensada como o conceito no corpo. E, o conceito Imagem poética, no corpo, é aquilo que de um modo ou de outro repercute, mais uma vez, em nós. A Imagem artística pode ser pensada como uma "coisa", que passa por nós, e que também emerge a partir de nós. Um acontecimento que age sobre nós, e que também vive em nós, e que pode ser pensado como uma espécie de atravessamento.

\section{Referências}

ALMEIDA, Vera Lucia Paes de. Corpo poético: o movimento expressivo em C.G. Jung e R. Laban. São Paulo: Paulus, 2009.

ARTAUD, Antonin. O Teatro e seu duplo. São Paulo: Martins Fontes, 1999.

BACHELARD, Gaston. $O$ ar e os sonhos: ensaio sobre a imaginação do movimento. São Paulo: Martins Fontes, 2001.

ELIADE, Mircea. Imagens e Símbolos: ensaio sobre o simbolismo mágico-religioso. São Paulo: Martins Fontes, 1991. 
GIL, José. Movimento Total. Lisboa: Relógio D'Água, 2001.

JUNG, Carl Gustav. O Espírito na arte e na ciência. Petrópolis: Vozes, 1971.

TARKOVSKI, Andrei. Esculpir o Tempo. São Paulo: Martins Fontes, 1998.

ZIMMERMANN, Elizabeth (org.). Corpo e Individuação. Petrópolis: Vozes, 2009.

Recebido em: 18/05/2017

Aprovado em: 27/09/2017 